\title{
Gêneros e sexualidades divergentes: escola e dinâmicas de subalternização da diferença $\sqrt{ }$
}

\author{
Romualdo da Silva Sales ${ }^{1}$ \\ Charliton José dos Santos Machado
}

\section{Resumo}

Este artigo tem como objetivo apresentar questões para reflexão sobre como os mecanismos de controle atuam sobre a construção das identidades sociais e sua diversidade, levando em consideração aspectos de gênero e sexualidade. Nossa abordagem dialoga com o trabalho de Foucault, particularmente em relação aos conceitos de aparelho de sexualidade, biopoder e seu gerenciamento. Esses conceitos ajudam a pensar sobre a prática, nas escolas, de técnicas de controle e subordinação contra pessoas que não realizam o roteiro descrito como performatividade binária de gênero e sexualidade. Nesse contexto, apresentamos alguns resultados de uma pesquisa de dissertação de mestrado intitulada: "A diferença vai para a escola: problematizando articulações discursivas e epistemológicas sobre marcadores sociais das diferenças das pessoas no espaço educacional", apresentada em 2019 pelo PPGS-UFPB. Trata-se de uma pesquisa de campo realizada em uma escola pública localizada no município de Remígio, no interior da Paraíba. Em termos metodológicos, esta pesquisa foi desenvolvida por meio de uma abordagem etnográfica, realizada por meio de observação participante e entrevistas com professores e diretores. É importante enfatizar que, nesta escola, a manifestação das diferenças de gênero e sexualidade das pessoas é interpretada por meio de concepções de regime de inteligibilidade binária construídas por discursos normalizadores. Portanto, dentro desse espaço escolar, indivíduos que quebram o desempenho binário de gênero são tratados como subordinados e punidos com retaliação.

Palavras-chave: Escola; Diferença; Gênero; Sexualidades; Performances.

\footnotetext{
${ }^{1}$ Doutorando em Ciências Sociais pela Universidade Federal de Campina Grande - UFCG. E-mail: romualldosales@gmail.com.

${ }^{2}$ Doutor em Educação pela Universidade Federal do Rio Grande do Norte - UFRN; professor titular da Universidade Federal da Paraíba - UFPB e pesquisado do CNPq (PQ - 1D), charlitonlara@yahoo.com.br.

"O presente trabalho foi realizado com apoio da Coordenação de Aperfeiçoamento de Pessoal de Nível Superior Brasil (CAPES) - Código de Financiamento 001”

"This study was financed in part by the Coordenação de Aperfeiçoamento de Pessoal de Nível Superior - Brasil (CAPES) - Finance Code 001"
} 


\begin{abstract}
This article aims to present issues for reflection on how control mechanisms act over construction of social identities and its diversity, taking into account aspects of gender and sexuality. Our approach dialogues with Foucault's work, particularly in relation to the concepts of sexuality apparatus, biopower and its management. These concepts help to think about the practice, at schools, of techniques of control and subordination against people who do not perform the script described as binary performativity of gender and sexuality. Within this context, we present some results of a research from master degree dissertation entitled: "The difference goes to school: problematizing discursive and epistemological articulations on social markers of people's differences in the educational space", presented in 2019 by PPGS- UFPB. It is a field research carried out in a public school located in the municipality of Remígio, located in countryside of Paraíba. In methodological terms, this research was developed through an ethnographic approach, executed through participant observation and interviews with teachers and Head teachers. It is important to emphasize that, at this school, people's gender and sexuality differences manifestation is interpreted through binary intelligibility regime conceptions constructed by normalizing discourses. So, inside this school space, individuals who break the binary gender performance are treated as subordinate and punished with retaliation.
\end{abstract}

Keywords: School; Difference; Gender; Sexualities; Performances.

\title{
Introdução
}

Pensar sobre identidades de gênero, sobretudo, de gêneros não binários e sexualidades divergentes ${ }^{3}$ resvala em questões que se conectam as produções discursivas e performativas que produzem transformações nas práticas sociais, sendo também informadas por estas. Destarte, a partir das reflexões de Dreyfuss e Rabinow (1995) sobre o pensamento de Michel Foucault, concebemos que os discursos não são dotados de autonomia em relação às práticas sociais, mas atravessados pelas figurações enlaçadas por elas, ao mesmo tempo em que as transformam, se configurando, em alguns aspectos, como um processo de dimensões interdependentes.

Em alguma medida, os discursos são produzidos, mas também produtores de instituições, valores e epistemologias que potencializam efeitos sobre sujeitos. Desta forma, os discursos transformam práticas sociais e são transformados por estas, tendo como ponto de toque o exercício de poder. Através desse processo, os discursos funcionam como um conjunto de forças que atuam sobre os sujeitos, atravessado por técnicas que operam sobre a lógica da governamentalidade. Estas não estão desconectadas de valores morais,

\footnotetext{
${ }^{3}$ Através das reflexões de Miskolci (2012), compreendemos por sexualidades divergentes, aquelas que tensionam as bordas do regimento político heteronormativo baseado no modelo heterossexual, reprodutivo e familiar.
} 
epistemologias e instituições que reverberam formas de controle sobre os corpos, gênero e sexualidades.

Desse modo, este artigo estabelece um diálogo com a obra de Foucault, sobretudo em relação aos conceitos de dispositivo de sexualidade, biopolítica e seus agenciamentos, deslocando o nosso olhar para apresentar o resultado de uma pesquisa de mestrado realizada em uma escola púbica do interior do estado da Paraíba. O objetivo é apresentar algumas problematizações acerca de produções sociais de identidades e diferenças, a partir da abordagem de Silva (2009), para quem, identidades e diferenças são produções relacionais, embora as identidades socialmente legitimadas pelas práticas discursivas sejam fortalecidas e as demais subalternizadas.

Essas questões nos auxiliam a pensar sobre a produção de identidades não binárias de gênero e sexualidades divergentes a partir do espaço educacional. Uma vez que, a partir das reflexões de Miskolci (2012), as escolas reproduzem dinâmicas de subalternização que reforçam os valores socialmente instituídos, incidindo sobre os sujeitos através de discursos que reforçam dicotomias e epistemologias que operam sobre seus corpos, identidades de gênero e sexualidades. Este processo produz efeitos traduzidos em dinâmicas de subalternização sobre aqueles que não se deixam colonizar pelas normas estabelecidas socialmente, resistindo às técnicas de controle impostas.

Nessa perspectiva, a partir das contribuições de Louro (2012), percebemos que as normas sociais produzem efeitos sobre os sujeitos, sobretudo operando a partir de instituições, entre elas, as escolas. Destacamos que estas, por excelência, atuam na conformação de identidades binárias de gênero e sexualidades pautadas no regime político da heteronormatividade. Segundo Miskolci (2012), este regime se configura como conjunto de estratégias de controle engendrado através de normas sociais, atuando na conformação de identidades de gênero e sexualidades construídos a partir do modelo heterossexual, reprodutivo e familiar. Em relação às identidades não binárias de gênero e sexualidades divergentes, as escolas atuam situando-as como anormais, uma vez que tensionam as bordas das normas dicotômicas, operando no terreno da ambiguidade, na fronteira.

Para esses sujeitos que borram as fronteiras de gênero e sexualidades, como mostra Silva (2011), percebemos que as escolas e o currículo não incorporam suas questões em suas pautas, sendo no máximo tolerados nesses espaços. Não há abertura para pensar manifestações da diferença como constituinte de identidades, embora as mesmas sejam 
construções relacionais, umas ganhando forma a partir da relação com as outras. O hegemônico no que tange identidades de gênero não é considerado uma identidade, mas a identidade, de onde as outras identidades divergem. Destarte, a lógica da convivência pacífica proposta pelo multiculturalismo para as escolas, apenas tenta esconder as dinâmicas de subalternização das diferenças sob a suposta neutralidade que as escolas advogam possuir.

Destarte, identidades de gênero são construídas a partir produções discursivas e performativas, tendo como referência cosmovisões e epistemologias dicotômicas que situam sujeitos no tempo e espaço. Em consonância com Butler (2003), trata-se de uma experiência discursivamente condicionada que se conecta com discursos culturalmente hegemônicos de base dicotômica. Ou seja, trata-se de um regime de inteligibilidade pelo qual identidades de gênero são performatizadas.

Em relação às sexualidades, segundo Miskolci (2012), estas são atravessadas pelas práticas discursivas que tentam situar sujeitos a partir da heteronormatividade. O mesmo autor observa que, o regime anteriormente mencionado não se impõe apenas sobre aqueles que borram as regras, mas também sobre aqueles que se encontram colonizados por elas, ou seja, sujeitos que desenvolvem performances que correspondem aos regimes de inteligibilidade que constituem as normas construídas socialmente. Em relação às escolas, percebemos que as mesmas reverberam discursos que reproduzem as lógicas dicotômicas, situando os sujeitos que borram as fronteiras normativas como subalternos, toleráveis, embora, em alguma medida, permita investidas contra eles, deixando claro sua posição construída de forma hierárquica. Nesse sentido, sujeitos divergentes são tratados pela lógica da violência simbólica, quando não física por colegas e docentes que impõem sobre eles os padrões hegemônicos, ao mesmo tempo em que enquadram, através das normas dicotômicas, aqueles que desempenham práticas sexuais divergentes, mas não performatizam socialmente. Isto é, os sujeitos podem ser homossexuais, mas não devem performatizar, tensionar ou mesmo quebrar as performances de gênero e sexualidades socialmente legitimadas.

Como mencionado, a narrativa que se segue faz parte de uma pesquisa realizada numa escola pública no interior da Paraíba. Em termos metodológicos, a estratégia utilizada para coleta de dados é de base etnográfica desenvolvida através de observação participante e entrevistas. O objetivo se volta para perceber como os discursos operam na produção de corpos e subjetividades no espaço escolar, incidindo sobre os marcadores sociais da 
diferença de gênero, sexualidades e raça, embora para este texto, apenas os dois primeiros sejam enfatizados.

A abordagem etnográfica foi relevante para perceber como os discursos operam nas extremidades, como eles conformam sujeitos a partir de exercício de poder. Foucault (1979) analisa como as relações de poder transformam as práticas sociais, produzem efeitos sobre os sujeitos, potencializando transformações, mas também sendo atravessado por estratégias de resistências e negociações. O mesmo auxilia pensar que o poder precisa ser analisado no exercício, no embate, nas zonas periféricas onde ele se espraia como rizoma e se dobra sobre os sujeitos, colonizando-os, mas também sendo desafiado, tensionado.

A narrativa que segue problematiza algumas questões sobre como mecanismos de controle atuam de forma mais incisiva sobre alguns sujeitos. Assim, para fins de preservação de anonimato, os nomes apresentados não correspondem aos dos participantes da pesquisa, tendo como objetivo a preservação de suas identidades, respeitando os princípios éticos em pesquisa envolvendo seres humanos.

\section{Considerações sobre o trabalho de campo}

A pesquisa que apresentamos foi desenvolvida em 2018, em uma escola pública de Remígio, município situado no interior o estado da Paraíba. Trata-se de uma escola da rede municipal que concentra aproximadamente $60 \%$ dos estudantes do ensino fundamental II, funcionando nos turnos matutino e vespertino com turmas do $6^{\circ}$ ao $9^{\circ}$ ano, recebendo 765 estudantes matriculados na modalidade regular. A escola fica localizada no bairro Bela Vista, próximo ao centro da cidade. Os estudantes da instituição são oriundos da zona rural e urbana, predominantemente integrantes de famílias de baixa renda. A faixa etária dos mesmos encontra-se entre 10 e 18 anos, distribuídos em 24 turmas, 12 turmas por turno. Em relação ao quadro docente, os dados relevam que aproximadamente 63\% são professoras e 36\% professores, predominando funcionários do quadro efetivo do município.

O trabalho de campo foi desenvolvido em 2018, mas os contatos junto à Secretaria de Educação do município foram iniciados ainda no segundo semestre de 2017. Inicialmente, entramos em contato com um membro do poder legislativo do município objetivando conseguir estabelecer contato com o representante da Secretaria de Educação. 
Ao estabelecer contato, fizemos algumas visitas à secretaria para formalizar a autorização para a pesquisa de campo. Em uma delas ficamos aguardando para sermos recebidos pelo secretário e, observando o ambiente, percebemos que existe uma oração emoldurada, tratase do Pai Nosso. O texto fica localizado em um lugar central, onde todos e todas possam ver os ensinamentos e valores cristãos. Este fato nos remete às análises de Dreyfuss e Rabinow (1995), particularmente no tocante às transformações que os discursos produzem nas práticas sociais ao mesmo tempo em que são informados por estas, uma vez que, a instituição reforça valores cristãos e, em alguns aspectos, esses valores atravessam as práticas pedagógicas e curriculares das escolas orientadas pelo vínculo estabelecido com a Secretaria de Educação.

Pensando sobre essas questões, percebemos que as escolas não se configuram como neutras, embora operem como se possuíssem essas dimensões. Silva (2011) afirma que as escolas funcionam como um dispositivo que reproduz formas de controle, sobretudo sobre as manifestações da diferença. Assim, as diferenças são pensadas como fora dos padrões instituídos socialmente, embora devam ser respeitadas, mas o respeito se configura apenas como um discurso superficial, velando os mecanismos de agenciamentos que movem a maquinaria discursiva e performativa que atua na produção de identidades de gênero e sexualidades, oferecendo apenas a aparência do fenômeno.

Como afirma Deleuze (2011), é preciso perceber como funcionam os processos de agenciamentos, problematizando não apenas como os fenômenos se mostram superficialmente, mas ir além dos sentidos, procurando perceber os não-sentidos. Aquelas questões que não aparecem de imediato, mas que fazem as lógicas de agenciamentos funcionarem. Perceber as diferenças, nesse sentido, não apenas como formas divergentes de identidades, mas perceber quais mecanismos fazem com que esses processos aconteçam. Pensar o não pensável, refletir sobre as descontinuidades, as linhas de fuga.

Para pensar essas questões, a abordagem etnográfica se apresenta como importante para perceber como são construídas as tensões e negociações no espaço escolar. Como formas de controle produzidas através dos sistemas de verdades, das relações saber-poder como analisa Foucault (1979) afetam os sujeitos. Pensar sobre como o controle coloniza sujeitos, mas ao mesmo tempo é desafiado, tensionado e reconfigurado através de embates entre identidades de gênero e sexualidades hegemônicas e as manifestações das performances que quebram suas formas de dominação e resistem às mesmas. 
Pensando sobre a abordagem etnográfica para perceber esses processos, sobretudo a imersão no campo, estabelecemos um diálogo com Wacquant (2002) para pensar como tal abordagem poderia produzir potencialidades para perceber as nuances do objeto de pesquisa. $\mathrm{O}$ autor nos auxilia pensar como a imersão no campo potencializa perceber como as suas lógicas funcionam, embora seja um desafio pensar um espaço conhecido como a escola. É preciso desenvolver dimensões de estranhamento para perceber as dinâmicas que não apenas colonizam o campo, mas também os pesquisadores.

O trabalho de campo foi desenvolvido na escola através de observação participante de atividades, acompanhamento de aulas de todas as turmas - sem priorizar disciplinas específicas - nos turnos matutino e vespertino. Realizamos entrevistas como professores, professoras e gestores da escola objetivando perceber como lógicas de controle são compreendidas pelos mesmos, assim como as normas também os colonizam ao passo de serem reproduzidas através dos discursos que aparecem em suas enunciações. Isto é, perceber os sentidos que eles atribuem as suas práticas, suas compreensões sobre projetos como Escola Sem Partido, mas também questões que não aparecem superficialmente, mas que integram seus discursos e práticas sociais desenvolvidas.

Procuramos analisar também os discursos que fazem parte do projeto político pedagógico na instituição, objetivando perceber as nuances que orientam a mesma e como estes discursos se conectam as formas de controle sobre as performances de gênero e sexualidades. Tendo em vista que entendemos, em consonância com Foucault (2008), que os discursos se configuram, em alguns aspectos, como um campo de forças real que atua sobre a população, potencializando transformações importantes, ao passo que atravessam instituições, exercendo controle e formas de governo sobre os sujeitos.

\section{Arquitetura binária: desdobramentos sobre a construção física da escola e os atravessamentos de gênero e sexualidades}

A escola apresenta construção arquitetônica que, assim como outras instituições, reproduz dicotomias estabelecidas através do binário, masculino/feminino. Durante o trabalho de campo, percebemos que os banheiros apresentam espaços, cores e alguns artefatos que situam o binarismo de gênero de forma incisiva, especificamente, em relação ao feminino, se configurando como estratégias de controle sobre esses corpos. 
O banheiro feminino fica posicionado acerca de cinco metros da secretaria da escola, local estratégico que permite observação direta de funcionários da instituição. Outras questões que nos parecem relevantes para pensar desdobramentos de formas de controle sobre os corpos femininos se voltam para construção arquitetônica que dialoga com o imaginário social, no tocante a construção discursiva e performativa de gênero. O Banheiro feminino é construído num espaço físico menor, fechado por uma parede, apresentando apenas uma abertura que oferece acesso ao local. A parede que fecha o espaço recebeu pintura com cores diferentes em relação às cores padrão da escola e também possui alguns vasos com plantas e flores.

Os banheiros masculinos ficam situados fisicamente em um espaço aberto, pintados com cores padrão da escola, contando com uma ampliação o que faz com que sejam estruturados de forma a fornecer 'maior liberdade' para os garotos. Esses banheiros, também são atravessados por dinâmicas de subalternização, pois alguns garotos ficam próximos a eles, utilizando-os como pontos estratégicos para investir contra as meninas que por ali passarem ou se divertindo em ridicularizar garotos por eles denominados afeminados, bichas.

Essas questões nos remetem as reflexões de Colling (2013), para quem as construções arquitetônicas de instituições não se descolam de valores morais e desdobramentos socioculturais, mas são informadas por estes. Dessa forma, percebemos como a posição ocupada pelos banheiros reforça dicotomias e lógicas de dominação que poderiam passar despercebidas. A arquitetura fala de um discurso não enunciado verbalmente, mas potencialmente eficiente na conformação de identidades binárias de gênero e orientação sexual. Não existe neutralidade, apenas uma fantasmagoria que se diz celebrar a diversidade apelando para o discurso humanista e multicultural, mas no cotidiano as normas socioculturais dão o tom das relações sociais estabelecidas.

Concebemos a partir das reflexões de Bulter (2003), que gênero e sexualidades não se configuram apenas como construções socioculturais, mas como regime de inteligibilidade pelo qual sujeitos são percebidos. Nessa perspectiva, as dicotomias apresentadas pela arquitetura da escola se conectam com estratégias que resvalam em como as normas sociais compreendem os sujeitos, posicionando-os dentro de bases discursivas e epistemológicas que situam aqueles que não se encaixam as regras como divergentes, sendo 
toleráveis, mas não aceitos e respeitados como aparece em discursos oficiais em matéria de educação e currículo.

Em relação ao uso de espaços físicos da escola, percebemos que há uma distribuição binária de gênero na cantina da mesma no momento de destruição de lanche para os estudantes. Trata-se de um espaço localizado no final do pátio da escola, fechado parcialmente por uma parede o que contribui para redução de visibilidade no local. Ao organizar os estudantes para receber o lanche fornecido, a instituição distribui os mesmos em duas filas uma formada por meninos e outra por meninas. Entretanto, a fila formada pelos meninos ocupa um espaço maior, além de alguns destes lancharem dentro daquele espaço, enquanto as meninas ocupam um espaço menor e sofrem investidas de alguns garotos que desenvolvem performances que remetem a práticas sexuais direcionadas a elas enquanto nenhum funcionário da escola está por perto.

Para entender um pouco a percepção dos estudantes, procuramos um grupo de alunos do $9^{\circ}$ ano que estava conversando no pátio, indagando sobre porque não estavam na fila para receber lanche. Os membros afirmam que não costumam lanchar todos os dias. Continuamos nossos questionamentos, desta vez sobre a distribuição de alunos e alunas em duas filhas separadas por gênero. Neste momento o grupo formado predominantemente por meninas responde de forma unânime: "achamos bom, porque os meninos empurram muito". Perguntados se gostariam de ficar juntos na fila enquanto aguardam a distribuição de lanche, responderam que sim, mas repetiram o argumento que os meninos empurram muito. Por fim, argumentaram que sempre foi assim e não percebem nenhum problema.

A partir dessas questões, percebemos que a ocupação dos espaços na escola é informada pelas construções discursivas e performativas que se conectam como valores socioculturais traduzidos em normas que atuam como biopolítica ${ }^{4}$ sobre os sujeitos. Para o feminino e não menos para aqueles garotos que quebram as performances de gênero, os espaços menores, as manifestações de violência e assédio. Para os meninos performativamente masculinizados e heterossexuais os espaços de poder e dominação. Essas questões nos remetem as análises de Louro (2012) ao afirmar que a construção de

\footnotetext{
${ }^{4}$ Foucault (2008) denomina biopolítica como uma atividade de Estado, ação política empreendida a partir da Modernidade que produz potencialidade de governamentalidade sobre a dimensão biológica da vida dos sujeitos, direcionando-se a população.
} 
performances de gênero passa pela formação de uma base discursiva, performativa e epistemológica que sustentam formas de dominação, produzindo efeitos na vida dos sujeitos, sobretudo situando-os no tempo e no espaço.

Durante o intervalo para a distribuição de lanche na escola, percebemos que grupos de garotos mais robustos acompanhados por alguns de estatura física menos expressiva caminham por toda escola, entrando nas salas de aula, se divertindo em assediar meninas ou investir contra outros garotos, sobretudo aqueles que desenvolvem performances não binárias de gênero. Acompanhamos casos em que garotos de 15 a 17 anos agarravam garotos menores desenvolvendo performances carregadas de sensualidade e sexualidade, esfregando seus corpos nos mesmos, forçando-os a permanecer naquela posição de subalternização. A partir desses casos, percebemos que alguns garotos de pequena estatura física optam por ficarem nas salas, como forma de proteção contra possíveis investidas de outros mais robustos, embora esta estratégia, algumas vezes, não obtenha sucesso.

Os mesmos grupos também se reúnem em um corredor próximo ao banheiro masculino, se divertindo em ridicularizar outros garotos, investindo contra eles, forçando a entrada destes nos banheiros e afirmando que irão manter relações sexuais com os mesmos, utilizando termos como: "vou comer agora". O discurso reforça a ideia de passividade e fragilidade de garotos menos robustos, associando-os a uma figura que pode ser penetrada, sobretudo quando se trata de garotos que performatizam identidades não binárias de gênero e sexualidades no convívio social.

Destarte, em consonância com Miskolci (2012), concebemos que as normas sociais atuam sobre os sujeitos produzindo efeitos, colonizando-os e potencializando desdobramentos. As performances de gênero são atravessadas pelos discursos e práticas sociais, princípios de inteligibilidade que governam sujeitos de forma a produzir hierarquias que subaltenizam grupos, estigmatizando-os. Tais performances são agenciadas para fortalecer as normas hegemônicas incidindo sobre todos os sujeitos, embora, em alguma medida, atuem mais diretamente sobre os sujeitos que não se deixam colonizar pelas formas de dominação. Desta forma, as performances de gênero socialmente instituídas não podem ser quebradas sob pena de retaliação. Entretanto, os sujeitos podem desenvolver relações afetivas e sexuais com outros do mesmo sexo, desde que socialmente performatizem o que demanda as normas sociais de gênero. 
A escola, nesse sentido, encampa a reprodução de valores que garantem o funcionamento dessas dinâmicas, evidenciando punições sociais direcionadas para aqueles que quebram as performances de gênero e sexualidades. Assim os sujeitos que não desejam sofrer retaliações devem ser conformados a partir do regime político da heteronormatividade e performatizarem identidades binárias de gênero. Com isto, não estamos afirmando que se trata de um sistema fechado onde os sujeitos não podem desenvolver estratégias de resistência ou mesmo negociações de suas performances de acordo com suas interações sociais. Em consonância com as reflexões de Miskolci (2017), as relações sexuais entre pessoas do mesmo sexo fazem parte do cotidiano de muitos sujeitos que socialmente seguem o script marcado pelo binarismo de gênero, porém, o passar por $^{5}$ garante conviver socialmente sem sansões e desdobramentos negativos sobre a vida cotidiana. Não se trata de destruir o desejo homossexual, mas de potencializar estratégias de controle para que os complexos de engenharia social que produzem as normas sejam mantidos em funcionamento.

\section{Dinâmicas de subalternização de manifestações da diferença em sala de aula}

O trabalho etnográfico desenvolvido na escola nos proporciona analisar alguns casos de dinâmicas de subalternização em sala aula. Ao iniciarmos as atividades de observação participante nas salas de aula da escola, vivenciamos técnicas sutis de formas de controle sobre performances de gênero de um estudante do $9^{\circ}$ ano por parte de uma docente. Em consonância com Oliveira (1996), a observação participante ultrapassa a dimensão de geração de hipóteses, proporcionalizando a produção de conhecimento efetivo que perpassa o ver, o ouvir e não menos as reflexões da escrita do pesquisador que desenvolve pesquisas etnográficas. Através dela é possível captar sentidos, linguagem e nuances que compõem o campo de investigação.

Sobre o estudante mencionado anteriormente, trata-se de Walter, garoto negro que não performatiza identidade de gênero que se insere nos regimes de inteligibilidades dicotômicos, sendo considerado afeminado naquele espaço. Durante a aula, a professora

\footnotetext{
${ }^{5}$ Refletindo a partir das análises de Miskolci (2017), concebemos que o termo passar por remete as performances de gênero que segue o script marcado pelo binarismo, pautadas em uma heterossexualidade presumida socialmente. Não se faz necessário ser heterossexual, mas perfomatizar socialmente que segue o padrão estabelecido pelas normas sociais.
} 
Kelly pede que os estudantes desenvolvam atividades em sala, enquanto observa a turma. Nesse momento, Walter assim como algumas colegas não consegue ficar em silêncio, interagindo com as mesmas e se envolvendo em uma contenda com elas. Esta dinâmica era atravessada por insultos por parte de todos do grupo, entretanto, a docente após observar durante algum tempo chama atenção de Walter, excluindo as colegas desse processo. $\mathrm{O}$ estudante indaga a professora sobre o fato de não chamar atenção de suas colegas, sendo respondido pela mesma que afirma ver apenas ele provocando problemas.

A postura da docente apresenta viés de parcialidade, uma vez que os estudantes envolvidos na contenda não foram tratados da mesma forma. Posteriormente, através de diálogos com outros docentes, percebemos que Kelly expressa suas manifestações religiosas através de denominações evangélicas, participando ativamente de sua igreja. Nessa perspectiva, um campo de análise que se desvela para nós se volta para perceber como os valores morais e, sobretudo, religiosos afetam o espaço escolar. As performances de gênero desenvolvidas por Walter não fazem parte dos regimes de inteligibilidade que orientam as práticas sociais, discursivas e epistemológicas como evidencia Butler (2003). Nesse sentido, evidenciamos que as performances de gênero ao tensionar as fronteiras binárias colocam em evidência seu caráter de construção social não apenas no que se relaciona aos gêneros, mas também aos sexos, tendo em vista que estas questões passam pelo crivo de formas construídas para perceber socialmente os sujeitos.

Walter não sofreu violência física e simbólica apenas em sala de aula, mas em outros espaços da escola. Ao caminhar pelo pátio juntamente com suas amigas, o jovem é atacado com insultos e injúrias, voltadas especificamente para situá-lo como uma figura divergente, subalterna. Durante a observação, percebermos que Walter se isola dos colegas, ficando sozinho, expressando tristeza. As investidas contra Walter apresentam duas dimensões importantes. A primeira aponta para situá-lo como parte de um grupo estigmatizado, denominado LGBTQI+; a segunda aponta para as punições direcionadas contra aqueles e aquelas que quebram as performances de gênero socialmente legitimadas pelos regimes políticos de inteligibilidade.

Concebermos que essas técnicas de controle atravessam as instituições e são direcionadas para população, produzindo efeitos sobre os sujeitos. Foucault (2008) afirma que a população se configura como um espaço em que atuam táticas de poder, transformando práticas sociais através dos discursos normalizadores que potencializam lógicas de 
governamentalidade. Situar performances de gênero e sexualidades dentro desses mecanismos evidencia a produção de normas sociais, potencializando a compreensão e problematização dos efeitos de hierarquias de subalternização de manifestações da diferença.

As performances de gênero não apenas passam pelas lógicas de controle, mas também de negociações de suas manifestações. Durante a quarta semana de observação, acompanhando uma turma de $7^{\circ}$ ano do turno da manhã, percebemos que o aluno Victor de outra turma entra na sala acompanhado por um colega no horário de intervalo. Nesse momento, Daniel vai ao encontro do estudante afirmando que ele está propagando inverdades sobre uma de suas amigas. Victor nega, mas Daniel insiste e o garoto reage: "eu não falei nada, viado safado." Daniel ao ouvir esta frase se afasta sem reação.

Após esse momento que aconteceu durante o intervalo, a aula de Língua Portuguesa é iniciada na turma. O professor dirige a aula através de leitura de um texto sobre primeiro beijo, pedindo que os estudantes desenvolvam a leitura. Daniel inicia a leitura da primeira estrofe. Ao término da leitura, o docente pede que outro estudante leia a estrofe seguinte, afirmando que a segunda pessoa deve ter voz de homem, corrigindo-se posteriormente, de “outro homem”. Marcelo aluno da turma fala para Daniel que o professor falou que ele é homem e Daniel, por sua vez, fala que está sofrendo preconceito e, afirma que precisa ser a mais feminina da sala. Marcelo indaga Daniel sobre com quem foi seu primeiro beijo, se teria acontecido com um garoto ou uma garota. Daniel responde: "Não é da sua conta, foi com meu ficante, foi com homem, pois eu não iria beijar a sebosa de uma mulher." A aula segue sem intervenção do professor, embora a interação entre os alunos tenha adquirido relevo entre todos os alunos da turma que riam da interação.

Através da narrativa apresentada, compreendemos que existe um processo de negociação de performances apresentadas por Daniel. Miskolci (2017) afirma que as performances de gênero e sexualidades são atravessadas pelos regimes de visibilidades de gênero, portanto, os discursos normalizadores colonizam os sujeitos, embora os mesmos negociem suas performances em relação aos seus interlocutores. Daniel apresenta performances de gênero que destoa dos regimes de inteligibilidades construídos socialmente, entretanto, posicionou-se de modo a silenciá-las quando confrontado por Victor que o situa como subalterno. 
Um ponto relevante diz respeito ao lugar de enunciação e às tecnologias que são acionadas. Victor é considerado performativamente situado dentro dos padrões instituídos em relação às identidades de gênero e sexualidades, portanto, é deste lugar que ele situa Daniel como divergente. Essas dinâmicas colonizam os sujeitos, não apenas os que reforçam as normas, mas aqueles que tensionam suas fronteiras, haja vista que os segundos são estigmatizados e, de certa forma, internalizam alguns elementos desses processos, resistindo, mas algumas vezes reiterando-os.

Sobre o lugar de enunciação, vale fazer algumas ressalvas que nos parecem relevantes, tendo em vista que mesmo sendo situado como subalterno, Daniel utiliza-se de discursos carregados de misoginia para esquadrinhar e subalternizar o feminino. Percebam que Daniel classifica as mulheres como sebosas, porém não percebe que, de certo modo, ele também é subalternizado por lógicas similares. Nesse sentido, Gosfoguel (2008) afirma que, embora sujeitos possam ocupar em determinados contextos posição de subalternização, isto não quer dizer que suas enunciações vão partir desse espaço, tendo em vista que as normas sociais colonizam a todos, embora não da mesma forma e profundidade. Ou seja, sujeitos atravessados por dinâmicas de subalternização podem reforçar lógicas de dominação que os esquadrinham, haja vista as lógicas que os enredam e os posicionam no tecido social.

\section{Considerações finais}

É possível evidenciar que instituições sociais, em alguns aspectos, são agenciadas em processos de construções de regimes de inteligibilidade que se conectam com produções discursivas e epistemológicas de normas socioculturais. Particularmente, as escolas são relevantes mecanismos de controle sobre os sujeitos, produzindo efeitos importantes no processo de socialização, fornecendo algumas chaves pelas quais os sujeitos são situados socialmente no tempo e no espaço.

Nessa perspectiva, concebemos que as escolas se configuram como uma espécie de catalizador, potencializando construções de hierarquias no tocante aos processos relativos à produção de identidades e diferenças, fortalecendo as primeiras e situando as demais como nota de rodapé o texto oficial. Dentro desses processos, percebemos que os marcadores sociais da diferença de gênero e sexualidades são acionados como elementos 
atravessados por agenciamentos que resvalam em um conjunto de técnicas de controle direcionadas aos sujeitos, sobretudo aqueles que deslocam performances binárias de gênero e sexualidades.

Assim, os sujeitos que não performatizam identidades de gênero binárias são tratados como anormais pelos regimes de inteligibilidade socioculturais, construídos para conceber as identidades e diferenças produzidas discursivamente, tendo como plano de fundo a busca por uma coerência estabelecida entre corpos, sexos, gêneros e orientação sexual. Entretanto, tais regimes não impedem que os sujeitos desenvolvam práticas afetivas e sexuais como pessoas do mesmo sexo, tampouco procura extinguir o desejo homossexual, mas manter o regime normativo em funcionamento.

A escola se configura como um dispositivo biopolítico eficaz no processo de difusão de normas sociais. Essas normas atravessam não apenas as interações entre sujeitos, mas os próprios conteúdos que aparecem nas páginas dos livros e orientam os conteúdos das aulas. Durante a atividade de investigação, era perceptível como valores religiosos e morais eram misturados aos conteúdos de disciplinas e aos discursos dos professores e professoras. Para estes sujeitos nossa proposta de pesquisa que versa sobre questões de controle, tensões, negociações e resistências no tocante às performances de gênero e sexualidades foi tratada como interessante o que não deve ser confundido relevante.

O processo de socialização apresentado no contexto escolar não é neutro, mas atravessado por valores, discursos e técnicas de controle que atuam sobre os sujeitos. Nestes espaços, os valores socioculturais dão o tom das relações estabelecidas entre os sujeitos, sendo informados pelos regimes de inteligibilidades que orientam a construção de normas sociais. Assim, os sujeitos são socializados, em alguma medida, através de leituras binárias no que toca à construção social de identidades de gênero e sexualidades, que se conectam as mais variadas formas de violência física e simbólicas que incidem sobre aqueles sujeitos que quebram as performances de gênero. Portanto, inspirados na obra de Foucault situamos as escolas como relevantes dispositivos da sociedade de controle. 


\section{Referências}

BUTLER, Judith P. Problemas de Gênero: feminismo e subversão da identidade. (Trad. Renato Aguiar). Rio de Janeiro: Civilização Brasileira, 2003.

COLLING, Leandro. A igualdade não faz o meu gênero - Em defesa das políticas das diferenças para o respeito à diversidade sexual e de gênero no Brasil.

Contemporânea - Revista de Sociologia da UFSCar. São Carlos, v. 3, n. 2, jul.-dez. 2013, pp. 405-427.

DELEUZE, Gilles. Crítica e Clinica. (Trad. Peter Pál Pelbart). São Paulo: Etitora 34, 2011.

DREYFUSS, Hubert; RABINOW, Paul. Introdução. In: Michel Foucault: uma trajetória filosófica. Para além do estruturalismo $e$ da hermenêtica. Rio de Janeiro: Florense Universitária, 1995.

FOUCAUL, Michel. Segurança, Território e População: curso dado em Collègue de France. (Trad. Eduardo Brandão). São Paulo: Martins Fontes, 2008.

- Microfísica do Poder. (Org. \& Trad.

Roberto Machado). Rio de Janeiro: Edições Graal, 1979.

GROSFOGUEL, Ramón. Para descolonizar os estudos de economia política e os estudos pós-coloniais: transmodernidade, pensamento de fronteira e colonialidade global. Revista Critica de Ciências Sociais. Coimbra Portugal, 2008.

LOURO, Guacira Lopes. Gênero, Sexualidade e Educação: Uma perspectiva pósestruturalista. 14. ed. Petrópolis, RJ: Vozes, 2012.

MISKOLCI, Richard. Teoria Queer: um aprendizado pela diferença. Belo Horizonte: Autêntica, 2012.

Desejos digitais: uma análise sociológica da busca por parceiros on-line. Belo Horizonte: Autêntica, 2017.

OLIVEIRA, Roberto Cardoso. O Trabalho do Antropólogo: olhar, ouvir, escrever. Revista de Antropologia. São Paulo, v. 39, n. 1, 1996.

SILVA, Tomaz T. Documentos e Identidade: Uma introdução às teorias do currículo. Belo Horizonte: Autêntica, 2011.

, Tomaz T. Identidade e diferença: a perspectiva dos estudos culturais. 9. ed. Rio de Janeiro: Vozes, 2009.

WACQUANT, Loic. Corpo e Alma: notas etnográficas de um aprendiz de boxe. Rio de Janeiro: Relume Dumará, 2002. 